going on well, and the throat was quite clear, when, about a fortnight from the commencement of the attack, he became uneasy in the head, and, during the night, lost the use of the right arm and leg. The difficulty of swallowing was increased, and the speech was affected. He gradually recovered the use of the limbs, but had occasional uneasiness in the head, with somewhat of a wild expression and wandering. There was continued difficulty in swallowing; and, now and then, a violent fit of choking, as though some particle of food found its way into the larynx. It was not, however, clearly made out that this actually happened. I saw him on April 16th, after an interval of several days, and found extreme dyspnœea, caused evidently by mucus in the air-passages which he was unable to expectorate. He died that night. On post mortem examination, the fauces and larynx presented nothing very peculiar; the mucous membrane was smooth and pale. The trachea and bronchi, large and small, contained a great quantity of frothy mucus; but there were no other evidences of inflammation here or in the lungs. In the superficial part of the left cerebral hemisphere, corresponding with the upper edge of the temporal bone, was a small suppurated spot, with softening of the adjacent brain-substance.

CaSE vII. Sudden Effusion into Bronchi Supervening. An undergraduate caught cold, and had acute inflammation of the left tonsil, with a diphtheritic patch upon it, and swelling of the neighbouring absorbent glands and adjacent parts. The inflammation was so acute and painful, that I directed a few leeches to be applied, which gave some relief. The membranous deposit spread over the throat and palate, and then gradually cleared off; but the pain in swallowing increased. He could be persuaded to swallow only milk, and very reluctantly gargled or permitted any cleansing of the throat. Still, he held his ground for a fortnight; was able to walk about bis room; and went for a drive; so that we hoped he would gradually get better. There was no indication of uffection of the trachea or lungs, till one night he was attacked with cough, bloody expectoration, and dyepncea, with râles all over the chest. In the fluid ex. pectorated, we found some branching strings of tenacious mottled substance, which were evidently casts, in lymph, of the air-tubes. He could not swallow anything; and rapidly sank and died in the middle of the next day.

CASE VIr. Anasarca and Albuminuria quickly super. vening upon Slight Diphtheria. Miss -, aged 3, 8 healthy girl, had sore throat, with small white patch upon the left tonsil, and swelling of the neighbouring absorbent glands. The white patch excited the appre. hension of the surgeon, because it remained, and returned when removed. This was the state when I saw her a few days after. There was very little redness or swelling; but general weakness and unwillingness to swallow. At first, she improved a little under steel, with beef-tea, etc.; but then relapsed. The white patch in creased, and the breath became foul. At the same time, albumen appeared in the urine; general anasarca, prostration, and dyspnœa, quickly followed; and she died a fortnight from the commencement of the attack.

In each of Cases No. 2, 3, and 4, the operation prolonged life twenty-four hours. The time thus gained may be dearly purchased by tracheotomy; but is well worth the minor operation of removing the uvula (as in No. 3) or tonsils. The difficulty of breathing is often at first entirely due to the impediment caused by swelling of the fauces; and the question of affording relief by removal of the uvula or tonsils is, in some cases, well worthy of consideration. It is easily done, is unattended with danger, clears the way for the passage of air, so diminishing the labour of breathing, and has the advantage of lessening the amount of foul surface in the throat. It may sometimes answer instead of tracheo. tomy. I believe that in Case Ir, the removal of the ton. sils would have given as much temporary relief as was afforded by tracheotomy. Moreover, we must not forget that the irritation caused by the presence of a tube in the trachea may predispose to the extension of the malady in that direction. Nevertheless, the experience of others show that in a few cases life has been saved by tracheotomy.

The occurrence of albuminuria and anasarca have been repeatedly observed by others; and afford an interesting link between diphtheria and scarlet fever; that of general paralysis (as in Case I) has also been observed, not unfrequently, and has often been recovered from. Hemiplegia (Case vI) is more rare, and is a more alarm. ing symptom as it commonly indicates a definite lesion of some part of the brain.

The affection of the larynx and bronchi, with scarcely any. warning in the throat (as in Case Iv), has been observed by others. It is very deceptive. In treating that case, we had no idea that we were dealing with diphtheria. The true nature of the disease was revealed to us only by the post mortem appearances. Further experience will probably show the disease commencing at various parts of the body, or modifying the inflammatory affections of various parts.

I have not met with a description of diphtheria of the eye (No.v); though the condition has probably been observed by others.

The extension of the inflammation into the trachea and bronchi, and the consequent effusion of the diphtheritic membrane, or of mucus into them (Cases II, III, IV, VI, VII), is one of the most fatal tendencies of this formidable malady.

Cases of diphtheria were occasionally met with in former years. The following took place in the Norwich Hospital, while I was a student there in 1837. A man, aged 24, underwent amputation in the thigh in consequence of acute suppuration in and about the knee, following upon a contused wound. He was in a low, feverish state, and had slight sore throat, when the operation was performed. This increased, was attended with cough, dyspnoea, and delirium, and he died, apparently suffocated, two days after the operation. The soft palate, pillars of the fauces, and part of the pharynx, were covered with a distinct layer of dirty lymph adhering to the surface. The mucous membrane of the larynx, trachea, and bronchi, even to the smallest branches, was also coated with a layer of lymph. The csophagus was quite free.

\section{THE TREATMENT OF THE EARLY STAGES OF HIP-JOINT DISEASE IN CHILDREN.}

\section{By Wiruram Price, M.D., Margate.}

Having held the appointment of surgeon to the Infirmary for Scrofulous Children at Margate for some years past, I have enjoyed unusual opportunities of observing the varied phases of hip.joint disease occurring in children of strongly marked strumous habit. The object of the present notice is not to adduce a new method of treatment, but to direct attention, through the pages of the British Medicar. Journal, to the undoubted superiority of one plan of treating the earlier stages of morbus coxæ over all others; viz., the continued employment of the long splint.

Many provincial surgeons now discard the long splint altogether in the early stages of hip-joint disease, giving preference to splints made of gutta percha, leather, or pasteboard ; carefully moulded over the buttock, reaching somewhat above the ilium, and extending down the upper half or two-thirds of the femur. They argue that the patient is thereby enabled to take early out.door ex. ercise on crutches, and is saved a strict confinement to the wards of a hospital, which the long splint necessarily entails. That much benefit is derived from the gutta- 
percha and leather splints during a more advanced stage of the disease, no one will deny. But how, it may reasonably be questioned, can perfect immobility of a hipjoint be maintained by means of a splint which does not equally prevent movement of the knee and ankle joints of the same limb?

The long splint should reach from midway between the axilla and crest of the ilium to a few inches beyond the external ankle. It is best adapted while the patient is under chloroform; and, no matter how severe the previous pain or muscular contraction about the joint, speedy diminution of the more urgent symptoms, as a rule, ensues. The length of time required for its employment must necessarily vary in each particular case. I have now in the infirmary two children side by side, one having worn a long splint for nineteen weeks, the other but five weeks; in neither case does any trace of original mischief now exist.

In many old standing cases of hip-disease coming under my notice, I observe marks of previous severe counterirritation, produced by moxas, issues, and the like. I have long ago satisfied myself that these measures are not productive of any appreciable benefit, and in my own practice abstain from any external applica. tion save the actual cautery. This invaluable agent, applied repeatedly by dotting over the integument of the buttock and surrounding parts (not allowing, however, the heated iron to remain sufficiently long upon the surface to produce an eschar or slough), cannot be too highly extolled, more especially as a means for relieving the pain dependent upon commencing ulceration of the cartilages; the relief thus afforded being singularly marked.

The happy results attending the above plan of treat. ment in my hands induce me to believe that an earlier discrimination of the first symptoms of hip.joint disease (as a rule, not difficult to recognise), the sedulous employment of a long splint, together with strict attention to a well selected diet, would go far to diminish, if not the mortality, at least the deformities, resulting from advanced stages of a malady so common at all ages and amongst all classes of society.

\section{Cramsactions of 题rantbes.}

\section{SHROPSHIRE SCIENTIFIC BRANCH.}

COMPOUND COMMINUTED FRACTURE OF TIBIA FOLLOWED BY TETANUS: DIVISION OF INTERNAL SAPHENOUS NERVE : RECOVERY.

By SaMr. Wood, Esq., Senior Surgeon to Salop Infirmary, F.S.A., etc.

[Read Feb. 13, 1863.]

THE cases of recovery after an attack of traumatic tetanus are so rare, that anything which adds to our stock of resources in treating this fearful malady is interesting and valuable.

In the winter of 1859.60 , the cold was intense, for some days below zero, and for a long time only a few degrees above it. On December 14th, 1859, William $P$. Claridge, Esq., of Pitchford Park, aged 30-of strong muscular development, moderate in every respect, accustomed to hunt two or three times a week, and con. sequently in vigorous health-was standing upon a ladder placed against a rick of wheat, for the purpose of getting some rats out of the thatch, and when he was about eight or nine feet from the ground a rat bolted in his face. This startled him; he shrank back, overbalanced himself, and, to save falling, jumped backwards from the ladder. He thought his right foot had sunk into a hole in the ground; but on attempting to rise, he found bis leg broken, the bone protruding through his stocking and trousers, and the blood streaming from the wound. He lay upon the cold ground for nearly an hour, whilst a conveyance was being obtained to take him home, from which he was distant about two miles.

On examination, when put to bed, I found a serious compound comminuted fracture of the right leg, and the tibia and fibula protruding from the wound. Several fragments of bone were removed, and the wound had to be enlarged to reduce the fracture, when a piece splintered up the tibia three inches was found detached, and with some little difficulty removed. The limb was placed on a sling splint rolled up, and a lotion applied.

Dec. 15th. The limb was in good position; there was no discharge. No part of the dressing was removed.

Dec. 16th. There was no discharge from the wound. He said he thought he had taken a little cold from lying so long upon the ground, and his throat felt a little sore. The tonsils, looking redder than natural, were lightly touched with nitrate of silver. The bowels had not been moved. He had slept well.

Dec. 17th. The wound looked well. The lint had separated. There was no discharge. He complained off a little stiffness about the neck; and said the food was tough, and his teeth felt sore.

Dec. 18th. Early this morning, I received an urgent message from his uncle, Mr. Claridge of Pershore, who was staying a few days with him, to say that his nephew had had a most severe convulsion. The pain shot down the wounded limb; his neck and head were drawn back, and his jaws closed. The spasm was over when $I$ arrived; but he was in a state of great alarm, and begged not to be touched for fear of renewing the spasm. Walking across the room affected him, and his agitation was most painful to witness. He said that had the convul. sion lasted a minute longer, he must have died. $\mathbf{M r}$. Claridge, who is a surgeon practising at Pershore, had given our patient a dose of calomel and colocynth, and we followed it up with castor oil and an enema of turpentine. 'The attack was too evidently one of traumatic tetanus. The fracture was much displaced by the spasm, and the splint tilted to one side. The limb was most carefully replaced in its position. Two grains of muriate of morphia were dusted on the wound, and a warm fomentation of poppy-heads applied. He complained of great stiffness about the neck and down the arms.

Dec. 19th. He had had another spasm. The bowels had been largely and freely moved. The jaws were still stiff; and he had a sensation of numbness down the other leg. A grain of opium every three hours was or. dered.

Dec. 20th. The fomentation was still applied. There was no discharge from the wound, which was dusted twice daily with morphia. $\mathrm{He}$ was in a great alarm at any one approaching the limb, or walking quickly across the room. From a blacksmith's forge, at the distance of sixty or seventy yards from the house, he could feel every blow of the hammer upon the anvil vibrating through the limb. He had had two returns of the spasm. $\mathrm{He}$ thought the opium did not agree with him. Feeling confident that if some means could not be devised to arrest this fearful malady he would quickly sink, I put the question to myself : What nerve is likely to be injured or is irritated by the ends of the fractured bones? Suspecting the saphenous from its proximity to the injury, I examined the course of the anterior crural; and finding a considerable degree of tenderness, I followed it up until I came on the internal saphenous branch; and upon my pressing upon this nerve, be cried out, "that the pain shot right into the wound." Confident I had hit upon the right nerve, I proposed to his uncle to cut down upon and divide it. He agreed with me as to the hopelessness of the case under the present or usual treatment ; and having explained our views to the patient, I at once proceeded 